\title{
An observational study of the association between COVID-19 vaccination rates and participation in a vaccine lottery
}

Dajung Jun, Anthony Scott (corresponding author: a.scott@unimelb.edu.au)

Melbourne Institute: Applied Economic and Social Research

The University of Melbourne

\section{Abstract \\ Objectives}

Are financial incentives from entry in a vaccine lottery associated with a higher probability of vaccination for COVID-19?

\section{Design}

A cross-sectional study with adjustment for covariates using logistic regression

\section{Setting}

October and November 2021, Australia.

\section{Participants}

2,375 respondents of the Taking the Pulse of the Nation Survey

\section{Interventions}

Participation in the Million Dollar Vaccination Lottery

\section{Primary and secondary outcome measures}

The proportion of respondents who had any vaccination, a first dose only, or second dose compared to all other respondents

\section{Results}

Those who participated in the lottery were 2.27 times more likely to be vaccinated after the lottery opened on October $1^{\text {st }}$ than those who did not. This was driven by those receiving second doses. Lottery participants were 1.38 times more likely to receive their first dose after October $1^{\text {st }}$ and 2.31 times more likely to receive their second dose after October $1^{\text {st }}$.

\section{Conclusions}

Lottery participation is associated with a higher vaccination rate, with this effect dominated by a higher rate of second doses. There is a smaller insignificant difference for those receiving a first dose, suggesting lotteries may not be as effective at reducing vaccine hesitancy, compared to 'nudging' people to get their second dose more quickly.

\section{Strengths and limitations of this study}

- We use a nationally representative sample of individuals.

- We distinguish between the association between lottery participation and first and second doses.

- We adjust for a rich set of individual characteristics associated with vaccination status

- The strong association for second dose vaccinations may reflect some individuals who had already had scheduled their second dose after the lottery opened, potentially leading to an overestimate of the association. 
medRxiv preprint doi: https://doi.org/10.1101/2022.03.02.22271734; this version posted March 4, 2022. The copyright holder for this preprint

(which was not certified by peer review) is the author/funder, who has granted medRxiv a license to display the preprint in perpetuity.

All rights reserved. No reuse allowed without permission.

\section{Ethics statement}

This study was approved by the University of Melbourne Faculty of Business and Economics \& Melbourne Business School Human Ethics Advisory Group (Ref: 2056754.1). 
medRxiv preprint doi: https://doi.org/10.1101/2022.03.02.22271734; this version posted March 4, 2022. The copyright holder for this preprint

\section{Background}

The effectiveness of using financial incentives to increase vaccination rates for the SARSCOV-2 virus is uncertain. ${ }^{1-3}$ Vaccination lotteries were established to increase vaccination rates, including across at least 21 states in the United States in 2021. Most notable is the lottery in Ohio run during May-June 2021 with 5 x \$1 million prizes over five weeks. Four studies using state-level data on vaccination rates over time, and comparing states with lotteries with those with none, found lotteries were ineffective in increasing vaccination rates. ${ }^{4-7}$ Four studies found an increase in vaccination rates ${ }^{8-11}$, including one that found increases in vaccination rates in low-income counties in Ohio but not in high-income counties. ${ }^{9}$ One study examined the use of financial incentives across 24 states across the U.S., mainly including lotteries, and found no overall impact on vaccination rates. ${ }^{12}$

Our research uses individual-level data to examine the association between vaccination rates and participation in a vaccination lottery held in Australia in October 2021. The Million Dollar Vaccination Lottery $(\mathrm{M} \$ \mathrm{~V})$ was open to entries from $1^{\text {st }}$ to $31^{\text {st }}$ of October 2021 for those aged 18 years or over who were Australian residents. Unlike some U.S. lotteries where the whole population was automatically entered the lottery, in $\mathrm{M} \$ \mathrm{~V}$, each person entered voluntarily by completing a short webform providing their contact details. At entry, participants could already be fully vaccinated or have had the first vaccination. Proof of vaccination was not required at entry into the lottery though individuals had to tick a box on the webpage stating that they had at least their first dose. If they were chosen to receive a prize (a provisional winner), they were required to show proof of full vaccination in the form of a government-approved electronic vaccination certificate. To claim a prize full vaccination must have occurred before $13^{\text {th }}$ December, or no later than $13^{\text {th }}$ January, depending on the required interval between first and second doses, which may vary across States and be up to 12 weeks. Only one entry per person was allowed.

M\$V was funded by an alliance of philanthropic organisations coordinated by the Summer Foundation. The lottery had a \$AU 1 million (\$US 0.72 million) Grand Prize in cash and a total of 3,100 daily prizes of $\$ A U 1,000$, with a total prize pool of \$AU 4.1 million. Each entrant was eligible for the Grand Prize draw and the daily draw on the entry date. The daily prizes were in the form of a gift card that could be used at a range of participating stores. The lottery was accompanied by a \$AU 3 million marketing campaign led by Sayers that included peak-time TV, radio, and full-page national and regional newspaper advertising, extensive social media advertising, and outdoor media (e.g., electronic posters at bus stops and shopping centres). The campaign targeted culturally and 
linguistically diverse audiences and included advertising in languages such as Mandarin, Arabic, Cantonese, and Vietnamese, and areas with high populations of Indigenous people. As the campaign progressed, the targeting became more granular and nuanced in response to the analysis of data regarding the reach of the campaign, competition entrants, and vaccination rates in specific geographic locations throughout Australia. In response to concerns raised on social media about $\mathrm{M} \$ \mathrm{~V}$ being a scam, the campaign pivoted to engage and profile daily draw winners in paid and to provide social proof about the legitimacy of M\$V. When the lottery closed, 2,744,974 Australians had entered, representing $13.7 \%$ of the adult population.

The context of the lottery was when Australia was well on its way to meeting vaccination targets. Australia's vaccination program started in March 2021. On the $30^{\text {th }}$ of September, just before the lottery opened, vaccination rates had steadily increased to $77.8 \%$ percent of the population over 16 years old with a first dose and $54.2 \%$ with a second dose. New South Wales (NSW) and Victoria, the two most populous states, had experienced outbreaks since July 2021 and were under various forms of lockdown at the end of September, including night-time curfews in Victoria, closure of retail businesses and hospitality, and continuing bans on travel. Lockdowns in NSW were more targeted at specific LGAs with high case numbers. All eight states and territories agreed to a national roadmap on the $6^{\text {th }}$ of August, with states individually releasing precise targets of population vaccination rates that were linked to the lifting of restrictions throughout the last quarter of 2021, with some targets being at the time the lottery was open. For example, in Victoria, the targets were $70 \%$ of the population aged 16 and over, (reached on $21^{\text {st }}$ October), $80 \%$ (reached on $29^{\text {th }}$ October), and $90 \%$ of $12+$ years (reached on $18^{\text {th }}$ November) with second dose. These targets provided nonfinancial incentives to get a second dose (referred to as 'fully vaccinated' at the time) as restrictions were eased when targets were met, with restrictions largely non-existent after the $90 \%$ target was reached.

The lottery provided the potential to receive financial incentives to encourage receipt of the first dose for those not vaccinated and provided incentives to those with a first dose to schedule a second dose if they had not already done so. Those with a first dose may already have had their second dose scheduled during October given the recommended fixed interval between doses, and so the lottery would not influence this group unless they changed their scheduled appointment to receive their second dose earlier. There were also those with a first dose who had not scheduled their second at the time the lottery opened. Those who already 
had their second dose before the lottery opened could still enter the lottery, but their vaccination status would not be affected by the lottery.

\section{Methods}

Patient and public involvement statement. There was no patient or public involvement in this study.

Data and participants. The Taking the Pulse of the Nation (TTPN) Survey was used to collect data. This is run by the Melbourne Institute and was administered every week from April 2020 and every two weeks from January 2021. Each wave includes 1,200 respondents, so it is a repeated cross-section. This paper uses data from 2,400 respondents in Waves 44 and 45 conducted in November 2021 after the lottery was closed at the end of October.

Data were collected by a commercial provider using a mixed-mode procedure. For each wave, 400 respondents were interviewed by telephone, and 800 respondents completed a web survey. The survey provider constructed the sampling frame from a diverse set of continuously updated proprietary databases. The survey sampling procedure followed strict quotas for six states and the Australian Capital Territory (ACT). Each wave includes 600 men and 600 women, and the shares of respondents for each state and ACT are proportional to the population of that state or territory. Each survey wave takes up to six days until the gender/state quotas are reached. Waves 44 and 45 were in the field between $1^{\text {st }}$ and $6^{\text {th }}$ November and $15^{\text {th }}$ to 20 th November. The raw share of each state/location/gender/age-group strata in the survey sample is not necessarily the same as the share of this stratum in the population. For each survey wave, post-stratification inverse probability weights are calculated provided based on Greater Capital City Statistical Area (GCCSA) or 'Rest of State' for each state using respondents' postcode, age group (18-24, 24-35, 35-44, 45-54, 55-64, 6475), and gender.

Study design and hypothesis. This is a cross-sectional observational study that examines the association between entering the lottery and the probability of receiving a vaccination after the lottery opened on October 1 st. The study design exploits information on the month individuals received their first or second dose of a COVID vaccine which was asked in Waves 44 and 45 after the lottery had closed. 
medRxiv preprint doi: https://doi.org/10.1101/2022.03.02.22271734; this version posted March 4, 2022. The copyright holder for this preprint

Variables. Participants were asked the following questions during Waves 44 and 45 in November 2021 to determine their vaccination status. "Are you willing to have the COVID19 vaccine? (1) Yes, (2) No, (3) Don't Know (4), I have had the first dose of the vaccine only (5), I have had the first and second dose of the vaccine." If they answered option (4) they were asked the month of their first vaccination. If they answered option (5), they were asked the month of their second vaccination. They were separately asked, "Did you enter the Million Dollar Vax Lottery? (1) Yes, 2) No." The main outcome variable is binary and equal to one for those who reported receiving any vaccination (first or second dose) after the lottery opened in October and is zero for the rest of respondents (including those who remained unvaccinated or those who received their first or second dose before October). In addition, we also separately analysed those who had their first dose after the lottery opened and those who had their second dose after the lottery opened.

TTPN asks a range of questions known to be associated with vaccination status, so these were included as independent variables in the analysis. We include indicators for male, age categories $(25-34 ; 35-44 ; 45-49 ; 50-54 ; 55-64 ; 65-74 ; 75+)$, having a child under 18 , income categories $(25-50 ; 50-75 ; 75$ percentile+; refused), education categories (high school graduates; some college; university and above), and categories of the industry relative to those not in the labour force (agriculture; mining; manufacturing; electricity; construction and wholesale; retail; food services; transport; information media; insurance services; real estate services; professional, scientific and technical services; administrative services; public administration; education; healthcare assistance; arts and recreation services; other). Indicators for states (VIC, QLD, SA, WA, others (ACT, TAS, NT)) and living in a rural area are included. Indicators for financial stress, policy satisfaction (satisfied; not satisfied), voting preferences (liberal or national; labour; greens or democrats) are included, and an indicator for wave 45 (15 - 19, November).

The vaccination rates of individuals could be associated with the vaccination rates of others in their LGA through neighbourhood peer effects, the location of vaccination providers, and other LGA-specific factors. In addition, M\$V targeted LGAs with low vaccination rates, and so LGA vaccination rates would be associated with participation in the lottery. We, therefore, merge data on LGA-level vaccination rates using each respondent's postcode of residence. 
Statistical analysis. Data are analysed using logistic regression using the outcome variable (vaccinated after October $1^{\text {st }}, 2021$ ) and the above covariates as independent variables to adjust for observed differences between those participating in the lottery and those who did not. Separate regressions are conducted for those receiving their first vaccination after October $1^{\text {st }}$ and those receiving their second vaccination after October 1st. Results are reported as odds ratios and marginal effects of the difference in the probability of being vaccinated. We exclude respondents who did not know the month they were vaccinated.

\section{Results}

Of 2,400 respondents, 2,375 responded to the vaccination question. A further 13 respondents did not know the month they received their first vaccination, leaving 2,362 for the analysis of receipt of the first dose. At the time survey was completed in November, after the lottery had closed, $59.9 \%$ of all respondents had received two doses, $6.1 \%$ had only their first, and $22.3 \%$ were willing to be vaccinated but had not yet received their first dose, $7 \%$ were unwilling to be vaccinated, and $4.7 \%$ were unsure.

Table 1: Descriptive Statistics

\begin{tabular}{|c|c|c|c|c|c|c|}
\hline & \multicolumn{2}{|c|}{ Full Sample } & \multicolumn{2}{|c|}{ In lottery } & \multicolumn{2}{|c|}{ Not in lottery } \\
\hline & Mean & Std. & Mean & Std. & Mean & Std. \\
\hline Proportion receiving any dose after October $1^{\text {st }}(\mathrm{n}=2,362)$ & 0.252 & 0.434 & 0.393 & 0.489 & 0.224 & 0.417 \\
\hline Proportion receiving first dose after October $1^{\mathrm{st}}(\mathrm{n}=2,362)$ & 0.089 & 0.285 & 0.118 & 0.323 & 0.083 & 0.276 \\
\hline Proportion receiving second dose after October $1^{\text {st }}(2,375)$ & 0.208 & 0.406 & 0.337 & 0.473 & 0.181 & 0.385 \\
\hline Lottery entrant & 0.170 & 0.376 & 1.000 & 0.000 & 0.000 & 0.000 \\
\hline Male & 0.485 & 0.500 & 0.415 & 0.493 & 0.500 & 0.500 \\
\hline Age $18-24$ & 0.116 & 0.320 & 0.098 & 0.298 & 0.120 & 0.325 \\
\hline Age $25-34$ & 0.192 & 0.394 & 0.184 & 0.388 & 0.194 & 0.396 \\
\hline Age $35-44$ & 0.173 & 0.378 & 0.188 & 0.391 & 0.170 & 0.375 \\
\hline Age $45-49$ & 0.084 & 0.278 & 0.105 & 0.307 & 0.080 & 0.271 \\
\hline Age $50-54$ & 0.081 & 0.273 & 0.127 & 0.334 & 0.071 & 0.258 \\
\hline Age $55-64$ & 0.152 & 0.359 & 0.192 & 0.395 & 0.144 & 0.351 \\
\hline Age $65-74$ & 0.119 & 0.324 & 0.085 & 0.280 & 0.126 & 0.332 \\
\hline Age 75 above & 0.082 & 0.275 & 0.020 & 0.139 & 0.095 & 0.294 \\
\hline Having a child below 18 & 0.310 & 0.463 & 0.321 & 0.467 & 0.308 & 0.462 \\
\hline Not graduated high school/NA & 0.162 & 0.368 & 0.141 & 0.348 & 0.166 & 0.372 \\
\hline Highschool graduated & 0.175 & 0.380 & 0.152 & 0.359 & 0.179 & 0.384 \\
\hline Some college & 0.307 & 0.461 & 0.325 & 0.469 & 0.303 & 0.460 \\
\hline University and above & 0.357 & 0.479 & 0.383 & 0.487 & 0.351 & 0.478 \\
\hline Income: below 25 percentile & 0.188 & 0.391 & 0.131 & 0.338 & 0.199 & 0.400 \\
\hline Income: 25 - 50 percentile & 0.288 & 0.453 & 0.279 & 0.449 & 0.290 & 0.454 \\
\hline Income: 50 - 75 percentile & 0.251 & 0.433 & 0.252 & 0.435 & 0.250 & 0.433 \\
\hline Income: 75 and above percentile & 0.198 & 0.399 & 0.233 & 0.423 & 0.191 & 0.393 \\
\hline Income: refused & 0.075 & 0.263 & 0.105 & 0.307 & 0.069 & 0.253 \\
\hline Industry: agriculture, forestry and fishing & 0.014 & 0.119 & 0.011 & 0.105 & 0.015 & 0.122 \\
\hline Industry: mining & 0.008 & 0.089 & 0.011 & 0.105 & 0.007 & 0.085 \\
\hline Industry: manufacturing & 0.026 & 0.159 & 0.021 & 0.143 & 0.027 & 0.162 \\
\hline Industry: electricity, gas, water and waste service & 0.013 & 0.114 & 0.003 & 0.052 & 0.015 & 0.123 \\
\hline Industry: construction and wholesale trade & 0.043 & 0.204 & 0.051 & 0.220 & 0.042 & 0.200 \\
\hline Industry: retail trade & 0.071 & 0.257 & 0.092 & 0.289 & 0.067 & 0.250 \\
\hline Industry: accommodation and food services & 0.021 & 0.143 & 0.014 & 0.119 & 0.022 & 0.147 \\
\hline Industry: transport, postal and warehousing & 0.028 & 0.166 & 0.009 & 0.096 & 0.032 & 0.177 \\
\hline Industry: media and telecommunication & 0.025 & 0.158 & 0.026 & 0.158 & 0.025 & 0.158 \\
\hline Industry: financial and insurance services & 0.044 & 0.205 & 0.028 & 0.164 & 0.047 & 0.212 \\
\hline
\end{tabular}




\begin{tabular}{lcccccc} 
Industry: rental, hiring and real estate services & 0.009 & 0.093 & 0.006 & 0.080 & 0.009 & 0.095 \\
Industry: professional, scientific and technical & 0.043 & 0.203 & 0.045 & 0.208 & 0.043 & 0.202 \\
Industry: administrative and support services & 0.019 & 0.138 & 0.020 & 0.142 & 0.019 & 0.137 \\
Industry: public administration and safety & 0.022 & 0.146 & 0.033 & 0.178 & 0.019 & 0.138 \\
Industry: education and training & 0.039 & 0.194 & 0.053 & 0.223 & 0.036 & 0.187 \\
Industry: health care and social assistance & 0.061 & 0.240 & 0.082 & 0.275 & 0.057 & 0.232 \\
Industry: arts and recreation services & 0.011 & 0.104 & 0.016 & 0.126 & 0.010 & 0.099 \\
Industry: other services & 0.059 & 0.236 & 0.054 & 0.226 & 0.060 & 0.238 \\
Industry: don't know, refused, not in the labour force & 0.443 & 0.497 & 0.426 & 0.495 & 0.446 & 0.497 \\
Living in rural & 0.316 & 0.465 & 0.303 & 0.460 & 0.318 & 0.466 \\
NSW & 0.328 & 0.470 & 0.269 & 0.444 & 0.340 & 0.474 \\
VIC & 0.265 & 0.442 & 0.327 & 0.470 & 0.253 & 0.435 \\
QLD & 0.203 & 0.402 & 0.194 & 0.396 & 0.205 & 0.404 \\
SA & 0.071 & 0.257 & 0.059 & 0.235 & 0.073 & 0.261 \\
WA & 0.102 & 0.303 & 0.126 & 0.333 & 0.097 & 0.296 \\
ACT, TAS, NT & 0.031 & 0.174 & 0.025 & 0.156 & 0.033 & 0.178 \\
Fully Vaccinated rate by LGA & 78.450 & 13.979 & 79.774 & 11.593 & 78.178 & 14.407 \\
With Financial Stress & 0.436 & 0.496 & 0.448 & 0.498 & 0.433 & 0.496 \\
Satisfied with policy & 0.428 & 0.495 & 0.437 & 0.497 & 0.426 & 0.495 \\
Not satisfied with policy & 0.251 & 0.434 & 0.212 & 0.409 & 0.259 & 0.438 \\
Indifferent with policy & 0.321 & 0.467 & 0.351 & 0.478 & 0.314 & 0.464 \\
Voting liberal or national & 0.342 & 0.475 & 0.328 & 0.470 & 0.345 & 0.476 \\
Voting labour & 0.324 & 0.468 & 0.350 & 0.477 & 0.319 & 0.466 \\
Voting greens or democrats & 0.114 & 0.318 & 0.089 & 0.285 & 0.119 & 0.324 \\
Voting others/no preference & 0.219 & 0.414 & 0.233 & 0.423 & 0.217 & 0.412 \\
Wave 44 (1 - 6, Nov 2021) & 0.500 & 0.500 & 0.466 & 0.499 & 0.507 & 0.500 \\
Wave 45 (15 - 19, Nov 2021) & 0.500 & 0.500 & 0.534 & 0.499 & 0.493 & 0.500 \\
\hline Number of observations & 2,375 & & 439 & & 1,936 & \\
\hline
\end{tabular}

Notes: Numbers are weighted.

Table 1 shows the weighted descriptive statistics of the sample used in the analysis and compares those who participated in the lottery with those who did not. Seventeen percent of respondents participated in the lottery. After the lottery opened on October $1^{\text {st }}, 25.2 \%$ of respondents received a vaccination (either first or second dose). For those who entered the lottery, $39.3 \%$ received a vaccination after the lottery opened on October $1^{\text {st }}$, compared to $22.4 \%$ of those who did not enter the lottery. After the lottery opened, $8.9 \%$ of respondents received their first dose. The percentage of those who entered the lottery and who received their first dose after it opened was $11.8 \%$, compared to $8.3 \%$ for those who did not enter the lottery. The proportion who received their second dose after the lottery opened was higher at $20.8 \%$. For those who entered the lottery, $33.7 \%$ received their second dose after the lottery opened compared to $18.1 \%$ of respondents who did not enter the lottery.

Those who participated in the lottery were more likely to be female, slightly more likely to be under 35 , more likely to be between 50 and 64 years old, and less likely to be over 65 . Those who participated in the lottery were likely to have a higher income. There was also a higher proportion of lottery participants from Victoria.

\section{Table 2: Adjusted and Unadjusted Regressions}




\begin{tabular}{|c|c|c|c|}
\hline & $\begin{array}{l}\text { Any dose after } \\
\text { October 1st }\end{array}$ & $\begin{array}{l}\text { First dose after } \\
\text { October 1st }\end{array}$ & $\begin{array}{c}\text { Second dose after } \\
\text { October 1st }\end{array}$ \\
\hline $\begin{array}{l}\text { Adjusted analysis } \\
\text { Lottery entrant } \\
\text { (Odds Ratio, 95\% CI) }\end{array}$ & $\begin{array}{c}2.274 * * * \\
(1.727 \text { to } 2.994)\end{array}$ & $\begin{array}{c}1.376 \\
(0.911 \text { to } 2.080)\end{array}$ & $\begin{array}{c}2.314 * * * \\
(1.742 \text { to } 3.073)\end{array}$ \\
\hline $\begin{array}{l}\text { Change in probability } \\
(95 \% \mathrm{CI})\end{array}$ & $\begin{array}{c}0.155^{* * *} \\
(0.100 \text { to } 0.210)\end{array}$ & $\begin{array}{c}0.025 \\
(-0.009 \text { to } 0.059)\end{array}$ & $\begin{array}{c}0.146^{* * *} \\
(0.092 \text { to } 0.200)\end{array}$ \\
\hline $\begin{array}{l}\text { Unadjusted analysis } \\
\text { Lottery entrant } \\
\text { (Odds Ratio, 95\% CI) }\end{array}$ & $\begin{array}{c}2.249 * * * \\
(1.732 \text { to } 2.919)\end{array}$ & $\begin{array}{c}1.472 * \\
(0.990 \text { to } 2.190)\end{array}$ & $\begin{array}{c}2.300 * * * \\
\text { (1.756 to } 3.012)\end{array}$ \\
\hline $\begin{array}{l}\text { Change in probability } \\
(95 \% \mathrm{CI})\end{array}$ & $\begin{array}{c}0.169 * * * \\
(0.111 \text { to } 0.228)\end{array}$ & $\begin{array}{c}0.035 \\
(-0.004 \text { to } 0.074)\end{array}$ & $\begin{array}{c}0.156 \\
(0.100 \text { to } 0.212)\end{array}$ \\
\hline Number of observations & 2,362 & 2,362 & 2,375 \\
\hline
\end{tabular}

Table 2 presents the results from the unadjusted logistic regressions that include only the lottery dummy variable as an independent variable, and from the adjusted logistic regressions that include all covariates in Table 1 as independent variables (full results in Appendix 1). The differences between the adjusted and unadjusted models are small. Lottery participation is associated with a higher proportion of respondents having any dose after October $1^{\text {st }}$. Those who entered the lottery were 2.27 times more likely to have a vaccination after October $1^{\text {st }}$ compared to everyone else. This is equivalent to an increase in the probability of a second dose after October $1^{\text {st }}$ of 0.155 (95\% CI 0.100 to 0.210 : 15.5 percentage points) compared to everyone else. Lottery entry was associated with a 0.025 (95\% CI -0.009 to 0.059 ) increase in the probability of getting the first dose after October $1^{\text {st }}$, but this was not statistically significant in the adjusted analysis, with the association driven by people getting their second dose.

The full results (Appendix 1) show that males, those in older age groups, those with children under 18, those working in accommodation and food services, public admin and safety, and other services were less likely to receive any vaccine after October $1^{\text {st }}$ : that is they were more likely to have been vaccinated earlier. There is a strong age gradient suggesting that older people were more likely to get vaccinated before October $1^{\text {st }}$. Those in rental, hiring, and real estate services were more likely to get vaccinated after October $1^{\text {st }}$ compared to those who were out of labour force. 
Table 3: Association with participation in lottery

\begin{tabular}{|c|c|c|c|}
\hline & Odds ratio & \multicolumn{2}{|c|}{$95 \% \mathrm{CI}$} \\
\hline Male & $0.778 *$ & 0.592 & 1.023 \\
\hline Age $25-34$ & 1.044 & 0.646 & 1.686 \\
\hline Age $35-44$ & 1.228 & 0.748 & 2.015 \\
\hline Age $45-49$ & 1.336 & 0.764 & 2.337 \\
\hline Age $50-54$ & $1.877 * *$ & 1.081 & 3.261 \\
\hline Age $55-64$ & 1.333 & 0.808 & 2.198 \\
\hline Age $65-74$ & $0.542 *$ & 0.288 & 1.018 \\
\hline Age 75 above & $0.168 * * *$ & 0.067 & 0.420 \\
\hline Having a child under 18 & 0.903 & 0.663 & 1.230 \\
\hline HS graduated & 0.830 & 0.520 & 1.324 \\
\hline Some college & 1.057 & 0.692 & 1.615 \\
\hline University and above & 1.221 & 0.783 & 1.905 \\
\hline Income: 25 - 50 percentile & 1.344 & 0.873 & 2.069 \\
\hline Income: 50 - 75 percentile & 1.353 & 0.851 & 2.152 \\
\hline Income: 75 percentile and above & $1.563 *$ & 0.933 & 2.619 \\
\hline Income: refused & $2.133 * * *$ & 1.212 & 3.753 \\
\hline Industry: agriculture, forestry and fishing & 0.632 & 0.232 & 1.719 \\
\hline Industry: mining & 0.906 & 0.182 & 4.505 \\
\hline Industry: manufacturing & 0.524 & 0.225 & 1.218 \\
\hline Industry: electricity, gas, water and waste services & $0.147 *$ & 0.019 & 1.122 \\
\hline Industry: construction and wholesale & 0.837 & 0.440 & 1.590 \\
\hline Industry: retail trade & 1.078 & 0.670 & 1.734 \\
\hline Industry: accommodation and food services & $0.451 *$ & 0.188 & 1.082 \\
\hline Industry: transport, postal and warehousing & $0.209 * * *$ & 0.065 & 0.671 \\
\hline Industry: media and telecommunication & 0.696 & 0.318 & 1.525 \\
\hline Industry: financial and insurance services & $0.430 * *$ & 0.185 & 1.001 \\
\hline Industry: rental, hiring, and real estate services & 0.489 & 0.099 & 2.426 \\
\hline Industry: professional, scientific and technical & 0.701 & 0.357 & 1.375 \\
\hline Industry: administrative and support services & 0.736 & 0.328 & 1.650 \\
\hline Industry: public administration and safety & 0.986 & 0.457 & 2.128 \\
\hline Industry: education and training & 0.848 & 0.439 & 1.638 \\
\hline Industry: health care and social assistance & 0.886 & 0.528 & 1.486 \\
\hline Industry: arts and recreation services & 1.404 & 0.470 & 4.196 \\
\hline Industry: other services & $0.618 *$ & 0.355 & 1.077 \\
\hline Living in rural & 1.076 & 0.817 & 1.419 \\
\hline VIC & $1.728 * * *$ & 1.227 & 2.433 \\
\hline QLD & $1.645 * *$ & 1.026 & 2.635 \\
\hline SA & 1.395 & 0.821 & 2.371 \\
\hline WA & $2.134 * * *$ & 1.261 & 3.612 \\
\hline ACT, TAS, NT & 1.174 & 0.612 & 2.252 \\
\hline Fully vaccinated rate by LGA & $1.017 * *$ & 1.004 & 1.030 \\
\hline With financial stress & 1.105 & 0.840 & 1.452 \\
\hline Satisfied with policy & 0.999 & 0.734 & 1.361 \\
\hline Not satisfied with policy & 0.759 & 0.540 & 1.069 \\
\hline Voting liberal or national & 1.031 & 0.719 & 1.479 \\
\hline Voting labour & 1.117 & 0.794 & 1.571 \\
\hline Voting greens or democrats & 0.754 & 0.469 & 1.211 \\
\hline Wave 45 (15 - 19 Nov, 2021) & 1.060 & 0.816 & 1.375 \\
\hline Constant & $0.034 * * *$ & 0.010 & 0.114 \\
\hline
\end{tabular}

Notes: $n=2375$. Results are based on logistic regressions and are all weighted. Respondents who serve as a baseline for categorical variables are in the youngest age group (18 - 24), income below 25 percentile, education below high school, being out of labour force or do not know the industry that they are in, living in NSW, without voting preference, and indifferent policy satisfaction.

Table 3 examines who is more likely to participate in the lottery. Males were less likely to do so compared to females. Relative to those aged 18-24, respondents aged 50-54 were more likely to be in the lottery, while those older than 65 were less likely to enter. Compared to those in the lowest income quartile, people in the highest income quartile were more likely to enter the lottery. Those working in manufacturing, electricity, gas, water services, 
medRxiv preprint doi: https://doi.org/10.1101/2022.03.02.22271734; this version posted March 4, 2022. The copyright holder for this preprint

accommodation and food services, transport, postal and warehousing, and financial and insurance services were less likely to enter the lottery than those who were not in the labour force. Respondents in LGAs with higher vaccination rates were more likely to enter the lottery. Compared to those living in NSW, respondents living in Victoria, Queensland, and Western Australia were more likely to enter the lottery.

\section{Discussion}

This study finds evidence of a statistically significant association between lottery participation and receipt of vaccination after the lottery opened on October $1^{\text {st }}$. However, there was no association of lottery entry with having the first dose once the lottery opened, suggesting the lottery did not reduce vaccine hesitancy. The association was driven by those who had received a second dose after October $1^{\text {st }}$. This group includes those who had already made an appointment before October $1^{\text {st }}$ to receive a second dose after October $1^{\text {st }}$. This group was still able to enter the lottery but the lottery would not have influenced when they received their second vaccination. This may lead to an overestimate of the effect of lottery participation on vaccination rates. The other group are those who had previously received a first dose sometime before October $1^{\text {st }}$ and decided to schedule their second dose in response to the lottery incentives or had their second dose booked already but had it brought forward. We cannot distinguish between these groups in our data as we did not capture the month of the first dose for those who had a second dose, and so could not measure the interval between first and second doses. The mandated interval between the first and second dose varied across states, which we adjust for in the analysis, and the type of vaccine received.

Distinguishing between the effect of a lottery on first and second doses is important for policy as they imply different objectives and the targeting of policy towards different groups of the population. Policies targeting first doses relatively late in a pandemic are tackling vaccine hesitancy as well as access to vaccines, whilst policies targeting second doses are more about achieving population protection in a timely manner by improving access and 'nudging' people to get their second dose. Lotteries can potentially influence both and the M\$V lottery explicitly targeted LGAs with low vaccination rates and so was more focused on tackling vaccine hesitancy. However, vaccine hesitancy is determined by a complex range of factors that financial incentives do not directly address. Lotteries may be more effective as 'nudges' for those who are already motivated to get vaccinated but have not yet arranged their appointments. 
Our research adds to the literature using a unique and representative sample of individuals from Australia during the time when the M\$V lottery was open. Previous evidence from the U.S., including several evaluations of the Ohio vaccine lottery, shows mixed results using difference-in-difference study designs. Of five studies that examined first doses ${ }^{4-9}{ }^{11}$, three found evidence of an effect of lotteries. ${ }^{8911}$ Of two studies that examined second doses ${ }^{45}$, only one found an effect of the lottery. ${ }^{5}$ Two studies ${ }^{6}{ }^{10}$ used the total rate of vaccinations combining first and second doses and one of these found an effect ${ }^{10}$.

The Ohio lottery and M\$V were designed differently, implemented at different times during the pandemic, and may have had different marketing campaigns and this may influence the results. The whole population of Ohio was eligible to win and many may not have known about the lottery and so were not motivated to get vaccinated. In the U.S. at that time the rate of vaccination was slowing, suggesting a lack of motivation in the population. The $\mathrm{M} \$ \mathrm{~V}$ lottery, however, required individuals to enter and allowed individuals entry if they had already been fully vaccinated. In addition, October 2021 was a time when vaccination rates were steadily increasing and when vaccinations targets focussing on second doses ('fully' vaccinated) had been set by some states that were linked to the lifting of harsh lockdowns. Generally, the Australian population was more motivated to get vaccinated and the M\$V lottery added to this motivation. People who were already fully vaccinated may have interpreted the lottery as a reward for their patience during lockdowns and for their earlier decision to get vaccinated, and for this group therefore the lottery did not influence their decision to get vaccinated.

Our results found that those with higher incomes were more likely to participate in the M\$V lottery which is opposite to expectations. Those on lower incomes are more likely to participate in lotteries generally ${ }^{1314}$. Our result maybe because of the specific context of COVID-19 where a large proportion of the population was or had been in a severe lockdown, and so the lottery was also perceived as a reward for their patience and for already being vaccinated and that this perception was more widely held by those with higher incomes.

The results also showed that those in LGAs with higher vaccination rates were more likely to enter the lottery compared to LGAs with lower vaccination rates, again suggesting that those who might have already been vaccinated before October $1^{\text {st }}$ were more likely to enter. The 
M\$V marketing campaign targeted LGAs with lower vaccination rates. Our results suggest that targeted marketing to persuade people to enter a vaccine lottery could be less effective in vaccine-hesitant populations where vaccination decisions are determined by a more complex range of factors that influence access, information, and beliefs ${ }^{15}$. Vaccine lotteries could be more effective as 'nudges' for people to get their second dose more quickly.

We do not examine the overall vaccination rate but the timing of when people received their second vaccination, so our numerical results are not comparable to those from other studies that use changes over time in population vaccination rates or the number of vaccines administered. Our data are self-reported and there is a risk of over-reporting of vaccination rates due to social desirability bias. However, this is unlikely as our self-reported rate of second vaccinations of $59.9 \%$ in the sample is lower than official data at the time it was collected $\left(77.5 \%\right.$ on November $1^{\text {st }}$ and $87 \%$ on November $\left.30^{\text {th }}\right)$. This also raises concerns about the representativeness of our sample. Though our sample is representative of states and territories and uses weights based on location, gender, and age, it is from a commercial panel where respondents might be different from the general population who do not participate in commercial panel surveys in ways we do not observe that might be correlated with lottery participation or vaccine hesitancy. For example, $17 \%$ of our sample participated in the M\$V lottery compared to the national estimate of $13.7 \%$.

The role of financial incentives to increase vaccination rates remains unclear, with some evidence suggesting that direct cash transfers might be more effective than lotteries ${ }^{3131617}$, but would also be more costly to implement on a population level. Further research should directly compare lotteries and cash transfers with other strategies ${ }^{16}$ to increase vaccination uptake and reduce vaccine hesitancy, though such strategies depend on the context and the stage of the pandemic and may interact with other strategies to increase vaccination rates, particularly in vaccine-hesitant populations where other factors are likely to matter more than financial incentives. 
medRxiv preprint doi: https://doi.org/10.1101/2022.03.02.22271734; this version posted March 4, 2022. The copyright holder for this preprint (which was not certified by peer review) is the author/funder, who has granted medRxiv a license to display the preprint in perpetuity.

All rights reserved. No reuse allowed without permission.

\section{Funding and acknowledgments}

This research was funded by the Summer Foundation (grant number: N/A) and used data from The Taking the Pulse of the Nation (TTPN) Survey run by the Melbourne Institute: Applied Economic and Social Research, University of Melbourne.

\section{Authors contributions}

AS conceived of the study, secured funding, designed the survey questions, contributed to the analysis, wrote and revised the manuscript, and interpreted results. DJ prepared the data and conducted all statistical analyses, contributed to writing and revising the manuscript, and interpreting results.

\section{Competing Interests}

None declared.

\section{Data availability statement}

Statistical code for the analysis s available from the Dryad repository, DOI:

https://doi.org/10.5061/dryad.rv15dv495. TTPN Survey is a proprietary data set and researchers interested in replication need to seek access to the TTPN survey by contacting the Melbourne Institute.

\section{References.}

1. Jarrett C, Wilson R, O'Leary M, et al. Strategies for addressing vaccine hesitancy - A systematic review. Vaccine 2015;33(34):4180-90. doi: 10.1016/j.vaccine.2015.04.040

2. Kim HB. Financial Incentives for COVID-19 Vaccination. Epidemiology and Health 2021:e2021088. doi: 10.4178/epih.e2021088

3. Volpp KG, Cannuscio CC. Incentives for Immunity - Strategies for Increasing Covid-19 Vaccine Uptake. New England Journal of Medicine 2021;385(1):e1. doi: 10.1056/nejmp2107719

4. Dave D, Friedson AI, Hansen B, et al. Association Between Statewide COVID-19 Lottery Announcements and Vaccinations. JAMA Health Forum 2021;2(10) doi: 10.1001/jamahealthforum.2021.3117

5. Lang D, Esbenshade L, Willer R. Did Ohio's vaccine lottery increase vaccination rates? A pre-registered, synthetic control study: Mimeo, 2021.

6. Walkey AJ, Law A, Bosch NA. Lottery-Based Incentive in Ohio and COVID-19 Vaccination Rates. JAMA 2021;326(8):766-67. doi: 10.1001/jama.2021.11048

7. Sehgal NKR. Impact of Vax-a-Million Lottery on COVID-19 Vaccination Rates in Ohio. Am J Med 2021;134(11):1424-26. doi: 10.1016/j.amjmed.2021.06.032 [published Online First: 20210730]

8. Barber A WJ. Conditional Cash Lotteries Increase COVID-19 Vaccination Rates. 2021 doi: http://dx.doi.org/10.2139/ssrn.3894034

9. Mallow PJ, Enis A, Wackler M, et al. COVID-19 financial lottery effect on vaccine hesitant areas: Results from Ohio's Vax-a-million program. Am J Emerg Med 2021 doi: 10.1016/j.ajem.2021.08.053 [published Online First: 20210826]

10. Acharya B, Dhakal C. Implementation of State Vaccine Incentive Lottery Programs and Uptake of COVID-19 Vaccinations in the United States. JAMA Network Open 2021;4(12):e2138238. doi: 10.1001/jamanetworkopen.2021.38238

11. Brehm M, Brehm P, Saavedra M. The Ohio Vaccine Lottery and Starting Vaccination Rates. American Journal of Health Economics 2021 doi: 10.1086/718512 
medRxiv preprint doi: https://doi.org/10.1101/2022.03.02.22271734; this version posted March 4, 2022. The copyright holder for this preprint

(which was not certified by peer review) is the author/funder, who has granted medRxiv a license to display the preprint in perpetuity.

All rights reserved. No reuse allowed without permission.

12. Thirumurthy H, Milkman K, Volpp K, et al. Association Between Statewide Financial Incentive Programs and COVID-19 Vaccination Rates. Social Science Research Network 2021 doi: http://dx.doi.org/10.2139/ssrn.3912786

13. Herring M, Bledsoe T. A Model of Lottery Participation. Demographics, Context, and Attitudes. Policy Studies Journal 1994;22(2):245-57. doi: 10.1111/j.15410072.1994.tb01466.x

14. Fu HN, Monson E, Otto AR. Relationships between socio $\square$ economic status and lottery gambling across lottery types: neighborhood $\square$ level evidence from a large city. Addiction 2021;116(5):1256-61. doi: 10.1111/add.15252

15. Leask J, Carlson SJ, Attwell K, et al. Communicating with patients and the public about COVID $\square 19$ vaccine safety: recommendations from the Collaboration on Social Science and Immunisation. Medical Journal of Australia 2021;215(1):9. doi: $10.5694 / \mathrm{mja} 2.51136$

16. Razai MS, Chaudhry UAR, Doerholt K, et al. Covid-19 vaccination hesitancy. BMJ 2021:n1138. doi: 10.1136/bmj.n1138

17. Wong CA, Pilkington W, Doherty IA, et al. Guaranteed Financial Incentives for COVID19 Vaccination: A Pilot Program in North Carolina. JAMA Intern Med 2021 doi: 10.1001/jamainternmed.2021.6170 [published Online First: 20211025] 